\title{
HuMANITIES \\ Working with interpreters: \\ An important skill for medical students
}

Sonja MacDonald ${ }^{1,2}$ and Kim Blake ${ }^{1,2}$

I. Department of Pediatrics, IWK, Halifax, NS, Canada

2. Division of Medical Education, Faculty of Medicine, Dalhousie University, Halifax, NS, Canada

For health care providers, communication is a key

Faspect of interacting with patients and their family members. When a common language between health care provider and patient is not spoken, having a simple conversation, taking a history, or explaining a treatment plan or procedure becomes complicated and unclear. Language barriers mean information is more likely to be misunderstood, recommendations are less likely to be followed, and timely health care negatively impacted $^{1-3}$.

As a medical student, one interaction in particular in which a language barrier was present has resonated with me throughout my learning. During a pediatric elective, I was asked to take a patient history from the patient's parents. As I called the family into the clinic room, I quickly realized we did not share a common language. Thankfully, an interpreter had been booked for the appointment ahead of time. As we patiently waited for the interpreter to arrive, I attempted to make small chat and engage the child with activities while the family settled in the room. During that short time, I felt an increased sense of unease and uncertainty. As I fumbled my way through introducing myself and asking how they were, there was obvious confusion and worried looks, from the family and undoubtedly myself. As the interpreter arrived, there was a significant sense of relief and calmness that followed. The remainder of the appointment went smoothly and the family's concerns were heard and explored, with an agreeable plan made.

Not surprisingly, language differences have been identified as a barrier to accessing health care, whether it is screening, routine, or specialized care. Additionally, language barriers have been identified as affecting other social determinants of health such as employment and social supports, therefore also affecting income, social justice, and social isolation ${ }^{4,5}$. As future health care providers, understanding and knowing how to utilize strategies and supports that currently exist will allow students to help patients overcome barriers such as language and cultural differences, thereby improving health care access and promotion ${ }^{6,7}$.

In 2017, Canada welcomed over 280,000 new permanent residents which included immigrants and refugees. Of recent immigrants and refugees from 2015-2017, approximately 24-26\% did not speak basic English or French ${ }^{8}{ }^{10}$. Currently, there are over 200

languages spoken in Canada, and among immigrants the most common languages spoken include Tagalog, Mandarin, Arabic and Hindi ${ }^{11}$. Providing informed and inclusive health care necessitates that patients are both understood and understand their health care providers.

Interpreters ensure patients understand their rights within the health care system and ensure patients are receiving accurate information to make informed decisions regarding their care. Depending on the health care facility, there are varying interpreter and translation services available. Currently within Nova Scotia's health care system, the cost of interpretation services is free to patients and families. These services include telephone interpretation, face-to-face interpretation, and sign language interpretation. Additionally, as the IWK serves a larger population, French interpreters are available on site.

As students, key factors to know ahead of time when working with an interpreter include the following ${ }^{12}$ :

- The language spoken by the patient and family

- Nature of the encounter

- Whether an in-person interpreter is available or if a telephone interpreter is required

- Date, time, and length of time requiring an interpreter - book interpreter ahead of time if possible

- Appointments/interactions take longer, so allocate more time than usual to ensure the encounter is not rushed

- If patient does not speak or read any English, interpreting services can call the patient/ family for you to ensure they are aware of an appointment

- For future visits, make a note on the patient chart and the booking slip that an interpreter is needed to aid in facilitating the booking process

As a health care provider, interpreting session tips include the following ${ }^{12}$ :

- Speak directly to the patient, NOT the interpreter

- Like any other patient interaction, explain to the patient that their information is confidential

- Avoid the use of slang, jargon, or highly technical vocabulary

- Use shorter sentences with frequent pauses to 
allow the interpreter to render all information

- Be mindful of vocabulary differences, there may not be a direct word translation for common words or phrases. You may need to explain these in more detail

- Always ask if there are any questions. It is not the interpreter's responsibility to ensure the patient understands, so make sure to check with patient during and prior to completing the interaction

- Diagrams can be useful and help to explain the information. These can also be taken away by the patient

- A properly trained interpreter is the best interpreter. Using family or community members may bring biases and impair the accuracy and impartiality of the information and interaction

Finally, be respectful and conscious of cultural differences. Communication varies among different cultures and we should be open and receptive to cues and diverse practices. Should you have any questions, feel free to ask the patient or interpreter for guidance.

In reflection after my experience during my paediatric elective, I recognized that the sense of uncertainty was my fear of being unable to communicate and provide the best patient care I could for that family. I felt inadequate. I grasped to the means of basic non-verbal communication, smiling. If I could not take a history, then I would at least make them comfortable. Thankfully, with the help and support of an interpreter, the appointment was made possible and patient centered care was able to be provided.

\section{Acknowledgements}

Thank you to Melanie Miller, Office Manager at Nova Scotia Interpreting Services for providing a brief interview and information on this topic.

\section{References}

1. Cass A, et al. Sharing the true stories: Improving communication between Aboriginal patients and healthcare workers. Med J Aust. 2002;176(10):466-470. doi:10.5694/j.1326-5377.2002. tb04517.x

2. Jacobs E, Chen AHM, Stroger JH, Hospital J. The Need for More Research on Language Barriers in Health Care. 2006;84,(1):111133.

3. Brisset C, Leanza Y, Laforest K. Working with interpreters in health care: A systematic review and meta-ethnography of qualitative studies. Patient Educ Couns. 2013;91(2):131-140. doi:10.1016/j.pec.2012.11.008

4. Thomson MS, Chaze F, George U, Guruge S. Improving Immigrant Populations' Access to Mental Health Services in Canada: A Review of Barriers and Recommendations. J Immigr Minor Heal. 2015;17(6):1895-1905. doi:10.1007/s10903-0150175-3

5. Hynie M. The Social Determinants of Refugee Mental Health in the Post-Migration Context: A Critical Review. Can J Psychiatry. 2018;63(5):297-303. doi:10.1177/0706743717746666

6. Pottie K, et al. Evidence-based clinical guidelines for immigrants and refugees. CMAJ. 2011;183(12):E824-925. doi:10.1503/ cmaj.090313

7. Viruell-Fuentes EA, Miranda PY, Abdulrahim S. More than culture: Structural racism, intersectionality theory, and immigrant health. Soc Sci Med. 2012;75(12):2099-2106. doi:10.1016/j.socscimed.2011.12.037

8. Citizenship and Immigration Canada. 2018 Annual Report To Parliament on Immigration. 2018:1-45. http://www.cic.gc.ca/ English/resources/publications/annual-report-2015/index.asp.

9. Citizenship and Immigration Canada. 2017 Annual Report to Parliament on Immigration. 2017. https://www.canada.ca/ content/dam/ircc/migration/ircc/english/pdf/pub/annual-report-2017.pdf.

10. Citizenship and Immigration Canada. 2016 Annual Report to Parliament on Immigration. 2016.

11. Gouvernement du Canada. Linguistic Characteristics of Canadians. Stat Canada. 2014;(98). http://www12.statcan.ca/ census-recensement/2011/as-sa/98-314-x/98-314-x2011001 eng.cfm.

12. MacDonald S. Phone and Email Interview with Nova Scotia Interpreting Services, Melanie Miller, Office Manager. 